\title{
Extrability as a strategy for successful employment of people with disability
}

\author{
Evgeniya Kopalkina ${ }^{1, *}$, Natalya Iltakova $^{2}$, and Tatyana Kirillova ${ }^{3}$ \\ ${ }^{1}$ Baikal State University, Department of Sociology and Psychology, Irkutsk, Russia \\ ${ }^{2}$ Buryat State University, Department of Theory and History of Law and State, Ulan-Ude, Russia \\ ${ }^{3}$ Irkutsk State Transport University, Department of Information Systems and Information Security, Irkutsk, Russia
}

\begin{abstract}
This research is one of the attempts to understand the phenomenon of extrability, which means additional opportunities for people with disability, which are formed in the process of successful social adaptation and socialization, thanks to which people with disability, having experienced a deep psychological crisis, qualitatively change their lives. The paper describes and analyses the original practical experience of the autonomous non-profit organization «White Cane», established in 2010 in the city of Yekaterinburg (Russia), the founder of which is O. B. Kolpashchikov, who developed and put into practice the concept of extrability. The information base of the research of the problem of inclusive employment at the present stage of the development of Russian society was made up of scientific works of Russian researchers, public statistical data of the Federal Register of Disabled People and the Federal State Statistics Service for 2017-2021, the results of sociological studies of recent years. It is emphasized that extrability is at the stage of institutionalization and testing. But despite this, it can be concluded that extrability not only solves the problem of employment and the quality of life of people with disability. But it also creates prerequisites for the formation of a new segment of the open labor market, associated with the fact that new jobs and professions appear, in which if people without disability are involved, the quality of rendered services is significantly reduced.
\end{abstract}

\section{Introduction}

The problem of inclusive employment, especially in the context of an increase in the number of people with disability of working age, as well as the imperfection of inclusive legislation and insufficiently developed inclusive interaction between employers, the state, public organizations and people with disability themselves, is one of the complex social problems of modern Russian society that requires a serious integrated approach.

The development and widespread use of information technologies (IT) at the present stage of society's development has led to the emergence of new forms of employment, in which people with disability can also be successfully involved. This increases their employment prospects, the degree of their social mobility, the quality and standard of living, from which «only a desire to work is required» $[1,2]$. But as the research of E. G. Kopalkina, A. E. Dareev, N. V. Iltakova shows the problems and features of the employment of people with disability are related not only to the people with disability themselves, their motivation to work, the quality of their workforce, but more to the prejudice of employers about lower qualifications and labor productivity of people with disability, as well as the need to create special working conditions for them. This allows them to offer low-skilled and low-paid work, up to their causeless fear when employers evade the obligation to fill quota jobs, preferring to pay penalties [3].

In fact, the analysis of sociological studies allows us to note a high degree of interest of people with disability in employment, their real difficulties in finding a job independently, in contrast to healthy able-bodied people who often register with the employment service bodies in order to receive unemployment benefits and benefits for housing and communal services [4-8].

The problem of inclusive employment has a clearly expressed social character due to prejudice and discrimination on the part of potential employers, the solutions to which are primarily associated with a change in the attitude towards people with disability, the transition from understanding them as dependents with a psychology of submission and passivity and a complex of «unpaid debt» to the state to understanding them as full-fledged people with a sense of self-esteem and respect, with an active life position, able not only to help themselves, but also to be useful to society.

To date, the theoretical and methodological foundations for understanding the new social role of people with disability, a new model for solving their pressing problems are gradually being formed. For example, one of the new interpretations of an inclusive person is associated with the philosophical research of $\mathrm{E}$.

Corresponding author: kopalkina2017@list.ru 
L. Yakovleva, who, after analyzing the same-root words «inclusion» and «exclusion», concludes that exclusivity gives an inclusive person a unique individual style, is allowed to manifest itself in life [9].

But most of all, the experience of the autonomous non-profit organization «White Cane» (Yekaterinburg) under the leadership of the author of the concept of extrability, O. B. Kolpashchikov. He understands extrability as the abilities of people with disability that initially have a hidden character, but with proper inclusive interaction, they awaken and qualitatively change their lives (creating a family, self-education, participation in social projects, employment, creating their own social projects and non-profit organizations, etc.), is most indicative. When people with disability have greater independence in movement (without the help of healthy people), communication abilities develop (with representatives of different cultures, different social groups, the nature of social contacts is long-term, based on friendship and sympathy). Economic behavior changes (they invest personal funds in events and trips, pay for others, invite to lunch, buy clothes more often, etc.), the field of social activity expands (proposals for professional and creative activities that are not related to disability) [10].

It turns out that extrability is understood as additional abilities in people with disability, which 1) are formed due to the restriction of their life activity; 2) are formed as a result of their successful socialization and social adaptation; 3) represent special, unique knowledge, skills and experience that people without disability do not have; 4) are their competitive advantages in the labor market.

According to the concept of O. B. Kolpashchikov, representatives of all disability groups are characterized by the following extrabilities:

The extrability of people with visual impairments is an excellent memory, charm, touch, hearing, imagination development, the ability to generate non-standard solutions, developed analytical thinking, the ability to competently operate with a large amount of information, developed intuition, trust in the world.

Extrability of people with mental disorders sincerity, emotionality, openness, communication skills, sincere manifestation of creative talents, empathy.

Extrability of people with hearing impairments developed visual attention skills, inner concentration, attentiveness, expressive gestures, sensitivity to vibration, non-standard thinking, attention to detail, expansion of the field of vision, development of imagination through the expression of their feelings.

The extrability of people who move around in a wheelchair is perseverance, the ability to choose their circle where it is convenient for them, the skills of planning actions in case of obstacles, the search for creative abilities, is a subtle psychologist, communication skills are well developed.

Examples of people with extrability are workers with mental disability in a factory of juniper toys, furniture and household items, hearing aids, educators with mental disability in kindergarten. Among famous people is Daniel Kish, an American expert on echolocation and president of World Access for the Blind, a non-profit organization founded in 2000 with the aim of facilitating the lives of people with all forms of blindness and raising public awareness of their capabilities. Roman Aranin, Russian inventor, CEO of the Observer company produces and repairs rehabilitation equipment for the disabled; Franklin Roosevelt, the 32nd president of the United States, who moved in a wheelchair.

\section{Methodology and methods}

The theoretical and methodological basis for understanding the phenomenon of extrability was laid by the research of O. B. Kolpashchikov. He is the author of the concept of extrability, the president of the ANO «White Cane», founded in Yekaterinburg in 2010, the ideologist and head of the international project «Sails of the Spirit», one of the main organizers of various Russian and international congresses, exhibitions and conferences dedicated to the formation of an inclusive culture in modern society.

The main methods used in our research were the method of analyzing information resources, the method of statistical monitoring and the method of analyzing secondary data.

The method of analyzing information resources made it possible to describe, disclose and analyze the experience of the ANO «White Cane» (Yekaterinburg), which implements social projects aimed at developing and using the ability of the highest level of people with disability-extrability, information about which is presented mainly on the official website of the non-profit organization https://extrability.org/.

The method of analyzing secondary data was aimed at the results of sociological studies that reveal the current state of the problem of employment of people with disability, features, difficulties, causes and factors of their low level of employment. For the purpose of secondary analysis, data from five sociological studies were used:

- the results of a survey (Ufa, 2015, n=160) of people with disability in order to find out whether the rights of disabled people are violated in the field of labor and employment [3];

- data from a questionnaire survey of unemployed disabled people of working age (Tomsk Region, 20172019, $\mathrm{n}=1295$ ) to find out their readiness for a work arrangement (vocational training) and factors hindering the solution of this issue [5];

- the results of a sociological survey of disabled people (Vologda Region, 2018, $n=139$ ) in order to find out what determines the income level of working disabled people - the general situation on the labor market or their wage discrimination [6];

- data from a sociological survey of persons with disability (Lipetsk, 2018, $\mathrm{n}=110$ ), conducted on the basis of the organization of the All-Russian Society of Disabled People, in order to determine the degree of accessibility for them of the sphere of work and earnings and problems associated with their employment [7]; 
- the results of a questionnaire survey of workingage disabled people suffering from all major types of persistent disorders of body functions (Moscow, 2018, $\mathrm{n}=1001$ ), the results of expert interviews with employers using disabled people's labor; with representatives of disabled people's societies; the management of educational and rehabilitation institutions; representatives of non-governmental recruiting organizations (Moscow, 2018, $n=23$ ) in order to study the main obstacles to employment of people with disability and their causes [8].

Public statistical data of the Federal Register of Disabled People and the Federal State Statistics Service for 2017-2021 were also used in the work. Using the method of statistical monitoring, the trends of changes in the level of disability in the Russian Federation and changes in the indicators of the situation of people with disability in the sphere of labor and employment were determined.

\section{Results and discussion}

The current state of the problem of inclusive employment is characterized by the following trends and patterns:

- the predominant part of people with disability are those who received disability in adulthood as a result of labor injury, military trauma, general illness, during military service. As of July 01, 2021, there are $10,779,426$ people with disability in Russia, of which only $11.27 \%$ are disabled since childhood. The data according to table 1 show that this trend has continued over the past five years.

Table 1. Dynamics of changes in the number of disabled people since childhood for the period of 2017-2021 [11].

\begin{tabular}{|c|c|c|c|}
\hline Period & $\begin{array}{c}\text { Total number } \\
\text { of disabled } \\
\text { people }\end{array}$ & $\begin{array}{c}\text { Disabled } \\
\text { people since } \\
\text { childhood }\end{array}$ & $\begin{array}{c}\text { Percentage of } \\
\text { disabled people } \\
\text { since childhood }\end{array}$ \\
\hline 2021 & 10877073 & 1202171 & 11.06 \\
\hline 2020 & 11197175 & 1174588 & 10.49 \\
\hline 2019 & 11333570 & 1153801 & 10.18 \\
\hline 2018 & 11434818 & 1120127 & 9.8 \\
\hline 2017 & 11640876 & 1096522 & 9.38 \\
\hline
\end{tabular}

- low level of employment of people with disability in working age. As of June 01, 2021, the share of disabled people who are not working is $74.86 \%$. The data in tables 1 and 2 are presented as of January 1 of these years.
Table 2. Dynamics of changes in the number of working and non-working disabled people in working age for the period of 2017-2021 [12].

\begin{tabular}{|c|c|c|c|}
\hline $\begin{array}{c}\text { Perio } \\
\mathrm{d}\end{array}$ & $\begin{array}{c}\text { The number } \\
\text { of disabled } \\
\text { people of } \\
\text { working age }\end{array}$ & $\begin{array}{c}\text { Working } \\
\text { disabled } \\
\text { people of } \\
\text { working age }\end{array}$ & $\begin{array}{c}\text { Non-working } \\
\text { disabled people } \\
\text { of working age }\end{array}$ \\
\hline 2021 & 3848164 & 26.33 & 73.67 \\
\hline 2020 & 3448078 & 26.37 & 73.63 \\
\hline 2019 & 3513762 & 26.14 & 73.86 \\
\hline 2018 & 3548537 & 25.72 & 74.28 \\
\hline 2017 & 3603641 & 25.55 & 74.45 \\
\hline
\end{tabular}

The main obstacles to stable inclusive employment are not only the low economic interest of employers, and widespread social stereotypes and discrimination in society, but also the psychological attitude and motivation to work of people with disability themselves, which can be positively influenced by proper inclusive interaction, as the author of the concept of extrability $\mathrm{O}$. B. Kolpashchikov rightly believes.

The main projects of the ANO «White Cane» aimed at the formation and development of extrability are [13]:

- «Sails of the Spirit» (inclusive yachting) - a roundthe-world trip on a yacht with the participation of people with disability. This project has been implemented since October 2011, since the start of the first training in Croatia. Since 2015 there have been Open championships in inclusive sailing, where according to the rules of the championships, the team captain must be a completely blind person. In 2021, from September 25 to October 10 , the 17 th stage of this international humanitarian mission is planned, each of the stages includes active socio-cultural and educational activities along the route of the expeditions and within the framework of regattas (round tables, seminars, promotions, inclusive master classes, concert performances, art performances, flash mobs, exhibitions, etc.). To prepare the project participants, training camps on inclusive sailing are held, where, together with professional yachtsmen, inclusive teams study the theory and practice of maritime affairs.

- «Business City» is an inclusive youth business game aimed at finding your favorite business. This project is organized for schoolchildren, students, applicants during the academic year on the basis of a special school for the blind named after Martirosyan (Yekaterinburg). The game consists of two stages: acquiring skills (attending various master classes from massage and hairdressing to business consulting and marketing) and opening a business (a cafe, a beauty salon, a cinema, a psychological assistance center, etc., the tasks are to organize the work of your company, hire employees, launch an advertising company for your 
business and try to earn the maximum possible amount of game currency). At the end of the second stage, a competent jury selects the best companies and the best directors, who are awarded valuable prizes and cash prizes.

- Boris Khokhonov Gallery «Painting of the Blind» is a project to create a picture of a blind person paired with a sighted artist, the purpose of which is communication, emotional exchange, working out skills of inclusive interaction in creative processes, within which sighted artists are trained in a new way of developing creative abilities, a new vision of the world and a new technology for obtaining masterpieces. And blind artists are immersed in the collective (objective) unconscious to extract new, phenomenal information.

- «Bastone Bianco» is a culinary show of blind chefs, where the main characters are blind people, and the guests are sighted, open to new gastronomic sensations. Those who want to test themselves as blind chefs, blindfold their eyes and, under the guidance of experienced blind chefs, start cooking dishes. The most important goal of the Bastone Bianco culinary club is to help blind and visually impaired people adapt to an independent life through cooking and eating. In addition, Bastone Bianco has experience of successful cooperation with business; these are advertising campaigns to attract the attention of consumers.

- «Multimobility» is a project that includes master classes on urban mobility, competitions in urban orientation, support in the development of digital devices (GPS, voiced smartphones, tactile sound cards, specialized software), maintaining a database of people with disability who work and are ready to advise on social and labor issues, forming an active life position, teaching people with disability to conduct master classes, public speaking skills, self-presentation.

- "Formation of an inclusive culture in the digital space" is a project aimed at training employees and volunteers in the competencies of working online and creating conditions for the implementation of projects in a hybrid format aimed at socialization through the involvement of representatives of different social groups (coaches, participants, partners, presenters, specialists, volunteers) in an inclusive interaction in order to implement activities in a remote format, obtain new opportunities for education and employment.

- «Youth Inclusive Games: A New Generation», which have been held in various formats in the Sverdlovsk Region since 2012 at the sites of the Ural State Forestry University and the Prometheus summer health camp. The aim of this project is to increase social and business activity, trust and mutual respect between young people with disability and their healthy peers through inclusive sports and cultural events. The program of the project includes sports and creative competitions of participants, presentations and exhibitions, performances of Russian and foreign performers, blindfolded bicycle tandem races; a mysterious «Dark Room»; the most delicious «Cooking Show»; interactive master classes; advanced gadgets of modern disabled people; beautiful vocals and incendiary dances; virtuoso playing of musical instruments; contests and prizes; funny flash mobs, etc.

- «School of Masters of Inclusion» is an educational program aimed at improving the quality of an accessible environment and inclusive interaction through the formation of communicative inclusive competencies among employees interacting with people with disability in the process of practice-oriented training with the participation of coaches from among the disabled. The program includes the following modules: 1) «The basics of inclusive communication, problems and opportunities when interacting with people with disability», 2) »Basic rules for communicating with people with disability: specifics and features».

«MAVIL» (Youth Environmental Volunteer Inclusive Camp) is an inclusive project that has been held in Yekaterinburg and other cities of the country since 2016. MAVIL is organized according to the type of stationary tent camp, whose activities are aimed at the formation of an ecological culture, the development of volunteerism, the formation of an inclusive culture, through the creation of events where representatives of various social groups interact. People with disability, people with various types of addiction who have undergone rehabilitation are on a post-rehabilitation program, business representatives, creative figures, heads of public organizations, government officials, active residents of the region.

In 2017, the ANO «White Cane», with the support of the Rosa Luxemburg Foundation Branch in the Russian Federation, published the first issue of the magazine « Inclusive Person», dedicated to the integration of people with disability. The journal became the bulletin of the First World Congress of People with Disability (Yekaterinburg, 2017). The debut issue covers world and Russian events in the field of interaction between people with disability, society and the state, includes personal stories of people with disability, and reveals details of the work of specialized non-profit organizations.

In 2020, a collective monograph «Extrability: a methodology for inclusive interaction of blind people» was published, including, consisting of 8 chapters. This focuses on the importance of organizing inclusive interaction, including changing the social role of blind and visually impaired people in the process of improving extrability during social adaptation, and also notes the role of extrability and reveals the essence of this social phenomenon [14].

Today, Yekaterinburg hosts an annual scientific and practical conference «Extrability as a phenomenon of inclusive culture», which, if in 2018 and 2019 had the status of an all-Russian conference with international participation. Then since 2020, there was a status of an international conference, bringing together representatives of countries such as Germany, Israel, France, Tajikistan, Latvia, Norway, the United States in promoting and developing a new theoretical, methodological and practical approach to inclusive interaction [15-17].

Thus, the activity of the ANO «White Cane» demonstrates to us a fundamentally different approach, the opposite of that followed by many countries, 
including Russia, focused more on an active, purposeful policy of stimulating employers. The accumulated world experience in the field of inclusive employment, the models of supported employment that have developed in different countries demonstrate greater or lesser effectiveness. But in general they contribute to overcoming discrimination of disabled people in the labor market, consolidating the idea of equal rights of all citizens in the public consciousness [18].

And although, as noted by researchers E. Y. Medvedev, E. A. Olkhina, such Western European countries as Germany, Belgium, Switzerland, France, have modern developed anti-discrimination legislation, and use a personalized approach. That takes into account gender, age and degree of disability, nevertheless, «state incentives in the field of employment, retraining and promoting self-employment of persons with disability, the number of unemployed among them is significantly higher than the general indicator» [19].

Further institutionalization and development of the extrability movement around the world, in our opinion, can contribute to changing and updating approaches to solving the problem of inclusive employment.

\section{Conclusion}

In conclusion, we can say that the concept of extrability in the scientific literature is revealed in the meanings of «new ideology», «new philosophy», «new model» of solving the problems of people with disability, it is emphasized that it is at the stage of approbation and institutionalization.

According to the results of the study, the following conclusions can be drawn on the problem of inclusive employment:

- the level of disability of the population both in our country and abroad is increasing every year;

- most of the people with disability are of working age;

- the level of employment of people with disability remains low;

- the process of institutionalization of extrability is revealed in the appearance of annual scientific conferences; the publication of a monograph and the journal «Inclusive Person»; participation in the extrability movement of people with disability from foreign countries, etc.

- the practical experience of the autonomous nonprofit organization «White Cane» (Yekaterinburg) is in many respects unique and exemplary for other institutions dealing with the problems of inclusion, inclusive interaction and inclusive employment;

- thanks to the extrability of people with disability, professions and jobs appear in the modern labor market, where only people with disability are accepted. We are not talking about those jobs that disabled people are employed in, provided with specialized equipment, and which could be occupied by healthy people, namely those that are not adapted to disabled people, new jobs, for which if, by involving people without disability, the quality of services is significantly reduced.

\section{References}

1. A.V. Gladysheva, O.N. Gorbunova, Prospects for the application of information technologies in the labor market of specific labor resources, Socioeconomic phenomena and processes, no. 10 (056), pp. 54-59 (2013)

2. N.E. Petrovskaya, Digital platforms as a dominant vector in the development of the global labor market, Control, vol. 9 (2), pp. 103-113 (2021)

3. E.G. Kopalkina, A.E. Dareev, N.V. Iltakova, Problems of employment of persons with disability at the present stage of development of Russian society, Social Competence, vol. 6 (2), pp. 223-233 (2021).

4. G.M. Khasanova, K.V. Polezhaeva, A.N. Khasanova, The problem of discrimination against people with disability in the sphere of labor and employment, International academic bulletin, no. 2 (8), pp. 99-103 (2015)

5. V.A. Perminov, S.N. Gruznykh, Experience in solving issues of employment of people with disability (by the example of the Tomsk region), Medical-Social Problems of Disability, no. 3, pp. 64-68 (2018)

6. L.N. Natsun, O.N. Kalachikova, Labor income of people with disability (by the example of the Vologda region), Bulletin of Ural federal university. Series economics and management, vol. 18, no. 1, pp. 127-143 (2019)

7. M.A. Gurina, A.D. Moiseev, A.S. Shurupova, On the issue of increasing the employment rate of persons with disability in Russia, Russian Journal of Labor Economics, vol. 6, no. 1, pp. 465-482 (2019)

8. O.A. Aleksandrova, Employers and people with disability in the capital's labor market: issues of effective interaction, Humanities and social sciences. Bulletin of financial university, vol. 10, no. 5, pp. 86-91 (2020).

9. E.L. Yakovleva, Experience of philosophical comprehension of an inclusive person, Karelian scientific journal, no. 4 (13), pp. 12-15 (2015)

10. I.F. Kasatskaya., O.V. Kolpashchikov, K.V. Barannikov, Theory and practice of extrability in changing the concept of the approach "We are not a disabled person, but a disabled person - to society and the state”, Inclusion in education, vol. 5 (17). pp. 40-59 (2020)

11. Federal State Information System Federal Register of Disabled People. [Electronic resource] URL: https://sfri.ru/analitika/chislennost (26.09.2021)

12. Federal State Statistics Service. [Electronic resource] URL: https://rosstat.gov.ru/folder/13964 (26.09.2021)

13. The site of the autonomous non-profit organization "White Cane". [Electronic resource] URL: https://extrability.org (26.08.2021)

14. K. V. Barannikov, O. B. Kolpashchikov, S. T. Kokhan, Extrability: a method of inclusive interaction of blind people, Chita: ZabGU, 313 p. (2020) 
15. Extrability as a phenomenon of inclusive culture: materials of the All-Russian scientific-practical conference with international participation (Yekaterinburg, December 12, 2018), Yekaterinburg: Publishing house Ural University, $124 \mathrm{p} \mathrm{(2019)}$

16. Extrability as a phenomenon of inclusive culture. Creating an inclusive culture in organizations: collection of materials of All-Russian scientific and practical conference with international participation (Yekaterinburg, December 12-13, 2019), Yekaterinburg: Publishing House "Azhur", 307 p (2020)
17. Extrability as a Phenomenon of Inclusive Culture. Formation of an inclusive culture in the digital space: Proceedings of the III International Scientific and Practical Conference (Ekaterinburg, December 10-11, 2020), Ekaterinburg, Publishing house Ural University, 193 p. (2021)

18. L.N. Natsun, "Supported employment" of people with disability: an overview of world experience, Bulletin of UrFU, series: Economics and Management. vol. 16 (4), pp. 663-680 (2017)

19. E.Yu. Medvedeva, E.A. Olkhina, Analysis of the system of employment of persons with disability and disability abroad, Psychological and pedagogical search, no. 2 (58), pp. 186-196 (2021). 